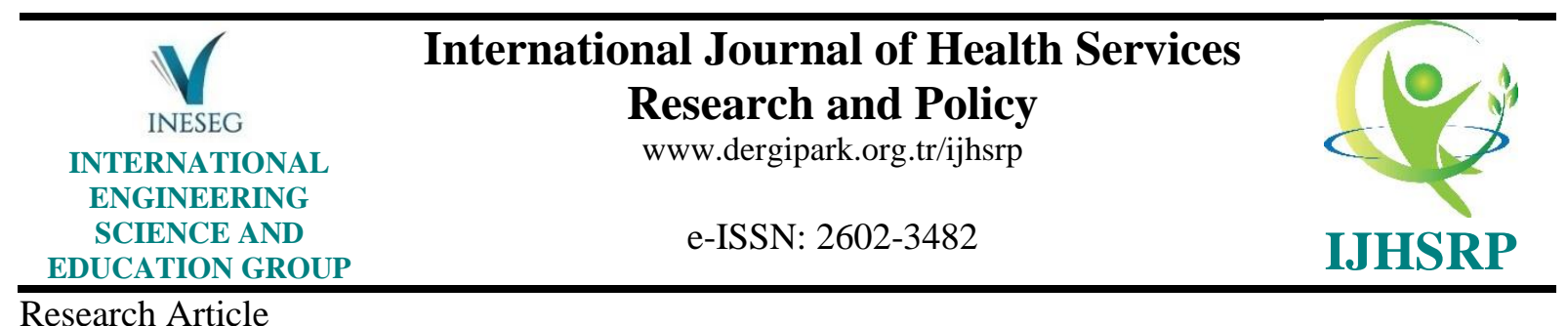

\title{
THE EFFECT OF TWO DIFFERENT METHODS IN TERMS OF MALPRACTICE: A RANDOMIZED CONTROLLED STUDY
}

\author{
Cagla YIGITBAS ${ }^{1 \text { (iD) Fadime USTUNER TOP }}{ }^{2}$ Aliye BULUT ${ }^{3}$ (iD \\ ${ }^{1}$ Giresun University, Faculty of Health Sciences, Department of Midwifery, Giresun/Turkey \\ ${ }^{2}$ Giresun University, Faculty of Health Sciences, Department of Nursing, Giresun/Turkey \\ ${ }^{3}$ Gaziantep Islamic Science and Technology University, Faculty of Health Sciences, Department of \\ Midwifery, Gaziantep/Turkey \\ Corresponding author; caglayigitbas@ hotmail.com
}

\begin{abstract}
The objective is to research the face-to-face method of education and the educational methods through information technology in the tendency and approach to medical errors and whether some characteristics create a difference in both these situations. It is randomized controlled intervention research with a pretest-posttest design. A power analysis was carried out and 60 individuals were included in the sampling. Pretesting was conducted through data collection tools before hospital implementations were commenced. The required interventions were conducted after hospital implementations were commenced. No interventions were made on the control group. The individual identificatory characteristics of the participants comprised the independent variables; the Medical Error Tendency Scale for Nurses (METSN) and Medical Error Attitude Scale (MEAS) comprised the dependent variables. The analyses were implemented via SPSS-22 program, and $p<0.05$ was regarded as the significance level. The mean age of the participants was $22.02 \pm 3.33$ (20-41). The pretest score from METSN was 217.51 \pm 15.14 , the posttest score from METSN was $220.18 \pm 15.39$, the pretest score from MEAS was $62.71 \pm 5.24$, and the posttest score from MEAS was $64.21 \pm 5.18$ in terms of Mean \pm SD scores. No difference was found in the pretest and posttest scores from METSN and MEAS of the variables of age group, gender, income, the place lived in over a long period, whether the job was selected in accordance with one's own preference, satisfaction with job selection. A moderately positive correlation was found between the pretest and posttest scores from METSN and MEAS. Type of education received and some of the socio-demographic characteristics researched do not constitute any difference in terms of the tendency and attitude to medical error and malpractice; nevertheless, the posttest scores of the intervention groups were high. Evaluation of whether clinical skills make a difference may be recommended.
\end{abstract}

Keywords: Medical error, malpractice, tendency and attitude, face-to-face education, via information technology education

Received: May 18, 2020 Accepted: June 30, 2020 


\section{Introduction}

"Medical Error (ME)" or "Malpractice (M)" as expressed in another definition used in the literature, which was first recorded in 1671 and commonly used as of the second half of the 20th century was derived from "Male" and "Praxis" words in Latin, and it means "erroneous practice" [1]. The Joint Commission on Accreditation of Healthcare Organizations has defined this situation as "harm done to the patient as a result of the fact that a professional providing health service has committed an inappropriate and unethical behavior, and s/he has acted insufficiently and negligently in professional implementations" [2]. A medical side effect occurs that prolongs the length of hospital stay and / or causes an additional problem during discharge from hospital in \%3.7 of the patients hospitalized and that harms them as a result. \%58.0 of these side effects are due to (ME) / (M). ME / M is not only the erroneous, deficient implementation of an intervention, treatment, or practice, but it also denotes a procedure that wasn't conducted although it should have been, or that was conducted although it shouldn't have been [3]. Nursing is a job with substantial workload arising from the effects of many negative factors emanating from the work environment. Reasons such as excessive workload, emotional stress experienced due to patients' problems, working with patients in need of intensive care, and in the process of dying and working in shifts in particular in nursing make working conditions harder. Working under difficult conditions may increase the $\mathrm{ME} / \mathrm{M}$ ratio of nurses during their nursing interventions [4]. According to a study specified in the national literature, medication errors that endanger patient safety are generally related to nurses [5-8].

$\mathrm{ME} / \mathrm{M}$ causes prolongation of the treatment, additional costs, and emotional damage emanating from the treatment of new disabilities or complications [9]. In addition, ME / M brings with itself the loss of the morale and motivation of health professionals, distrust in patients towards health staff, and dissatisfaction in society with the health system. It has been stated in the "report on patient safety" of the WHO that patients in various countries, including Australia, Canada, England, Germany, and New Zealand experience ME / M and undesirable events. The frequency of unexpected ME / $\mathrm{M}$ is between $\% 3.2$ and \%16.6 in these countries. One in every ten patients is seriously affected by errors committed during treatment; $\% 14.0$ of these errors result in death, and \% 70.0 of them result in various disabilities [10]. The training provided to the health staff is emphasized to have decreased ME / $\mathrm{M}$ in the literature $[11,12]$. Training on health can be provided today in many ways such as the traditional method or through information technology and information technology adventure has gained impetus, symmetry, mobility, and globality through new media technologies making the headlines since the 1960s [13]. Information technology can be defined as the use (obtaining) of modern knowledge in the electronic environment, which encompasses access, storing, data processing, and transfer or delivery [14]. Within this context, this study aims to compare whether face-to-face education method, preferred as an educational method since very old times and the method of information technology creates a difference in bringing ME / $\mathrm{M}$ tendency and attitude to desired levels. Whether some identificatory characteristics also make a difference in ME / M tendency and attitude will be determined through this study.

\section{2. Materials and Methods}

\subsection{Design}

The study is intervention research with randomized control encompassing comparison of pretest and posttest. It is oriented towards the comparison of the pre-intervention awareness level of nursing 
students in ME / M tendency and attitude with their post-intervention awareness level. The participants were randomly selected in this factually experimental design [15] defined as a two-factor mixed design with pretest-posttest control groups. The research design is also a mixed design relevant and irrelevant in itself. Since the participants were measured with respect to the dependent variable before and after the experimental implementation, it has a relevant pattern; since the measurements of the control groups made up of different subjects were compared to each other, it has an irrelevant pattern [16]. The population of the study was composed of all nursing students in their third year studying for their bachelor's degree in a state university $(\mathrm{N}=119)$. Nursing students in their first year were excluded from the study because they are not allowed to perform an invasive intervention, nursing students in their second year were excluded from the study since their professional skills have not reached the desired level. In the third year, the course of pediatric nursing is offered. Within the scope of this course implementation, ME / M likelihood increased since procedures to be conducted on groups of infants were in the forefront. It was assumed that the ME / M tendency and attitude of the participants to stay with the group bearing risk had diversified over time since there were pediatric patients. A power analysis was implemented through G-power, and the appointment of individuals to be included in the groups was determined via research randomizer.

\subsection{Inclusion criteria for volunteers to be included in the study}

Being a nursing student in the third year, having WhatsApp / Messenger application that is accessible, being in the procedure of pediatric nursing, not having any language barriers

Collection of Data: The minimum sampling size to be attained in accordance with the results of Gpower analysis is 51 individuals. For the purpose of increasing the representation ability of the sampling for the population, an extra $\% 20$ of the minimum sampling size was included in the study and the study was completed with 60 individuals. The number of groups in the research was designed to be three. Two of the groups were the intervention groups, and one of them was the control group (CG). The intervention groups were the Face-to-Face Education Group (FFEG) and the Information Technology Group (ITG). The simple random sampling method regarded [17] as valid and the best way of the selection of the representative sampling was used in the selection of the study groups. Groups, as specified below, were formed through Research Randomizer on the basis of a class list of 119 individuals. FFEG: 118., 117., 116., 111., 102., 92., 75., 74., 73., 66., 58., 57., 55., 52., 44., 34., 11., 10., 7., and 1. individuals ITG: 115., 114., 107., 105., 101., 93., 90., 88., 71., 68., 67., 63., 62., 48., 39., 32., 28., 24., 19., and 9. individuals $\boldsymbol{C G}$ : 113., 108., 104., 100., 99., 95., 91., 86., 84., 81., 72., 61., 54., 50., 46., 42., 29., 27., 5., and 3. Individuals. Before hospital implementations were commenced for all three groups, a pretest was conducted via Medical Error Tendency Scale for Nurses (METSN) and Medical Error Attitude Scale (MEAS). During the pretest, the participants were told to choose a nickname for themselves, and the posttest was implemented in accordance with these nicknames. After hospital implementations were commenced, the required intervention techniques were applied to the participants: Training made up of three parts were provided to the FFEG regarding ME / M tendency and attitude on a face-to-face basis. These parts of training included the definition and significance of $\mathrm{ME} / \mathrm{M}$, commonness and history of ME / M, the reasons why it is frequently observed with nurses, how it can be prevented, duties, authorizations, and responsibilities in preventing ME / M, the state of $\mathrm{ME} / \mathrm{M}$ in legal terms and what sanctions could be imposed. One part of the training was given by an expert nurse specialized in the field of occupational health and safety (in malpractice in particular); the 
other parts were provided by a faculty member in the field of pediatric nursing and by a faculty member that provided the course of occupational fundamentals and technique. The same tests were readministered as post-tests to all three groups at the end of four weeks. The materials of training were sent to the ITG through WhatsApp / Messenger in the form of PowerPoint presentations three times (for three weeks in total with a different subject for each week). It was ensured that the content of the training was the same as that of the training given to FFEG in order to prevent confusing impact. Whether the participants studied the presentation was determined and reinforced by the participants giving feedback through WhatsApp / Messenger. No interventions were made on the control group. The method of triple blinding was used in the study. Through this method, it was ensured that the participants, the narrator and the one implementing data entry and analysis did not know who was in which group.

Ethical Statement: All procedures performed in studies involving human participants were in accordance with the ethical standards of the institutional and/or national research committee and with the 1964 Helsinki declaration and its later amendments or comparable ethical standards. This study is approved by Bingöl University Ethics Committee ( 92342550/044; 19.06.2019)

\subsection{Database Analysis}

The situations of the participants researched in their form of individual identificatory characteristics comprised the independent variables of the study, and the questions measuring METSN and MEAS comprised the dependent variable of the study. Statistical Package for the Social Sciences22 program was used for the analyses. In statistical evaluations, number and percentage, values, and rank averages are given. Before normality analyzes, missing data and extreme value extractions were made. Then, histogram drawings were made for compliance with normal distribution, skewness, and kurtosis values were examined, and Kolmogorov-Smirnov analyzes were performed. Logarithmic transformations were applied since the data did not show normal distribution. However, it was observed that the total and sub-dimension scores of the scales did not fit the normal distribution. For this reason, non-parametric tests [Mann Whitney U (MWU) and Kruskall Wallis (KW)] were used in the research. The averages were provided with standard deviations; $p<0.05$ was regarded as the significance level.

\subsection{Tests Used in the Study}

Individual Information Form: It was produced by the researchers, and it was for determining the properties of the participants such as age, gender, habits, chronic illness, the place where s/he spent her/his life over a long period of time, her / his perception regarding her/his income, her/his preference of the profession and her/his state of satisfaction with the job, her/his perception of the reason for ME / M.

METSN: It was developed by Ozata and Altunkan [5] in 2010 for the purpose of measuring ME / M tendencies of nurses. The scale consists of 49 items. These items and their sub-items include " Medication and Transfusion Implementations" (MTI), "Falls" (F), "Hospital Infections" (HI), "Patient Monitoring / Material Safety" (PM / MS) and "Communication" (C). The scale is a 5-item Likert type. In the evaluation of the scale, the scoring range was determined as between $49-245$. It has been stated that this ratio can also be divided by the count of expressions if desired. It has been demonstrated that the higher the average score of the scale gets, the tendency of nurses for committing ME gets lower and that the lower the average score of the scale gets, the tendency of nurses for committing ME gets higher. It has been specified that the Cronbach's Alpha coefficient of the scale developed is .95. 
MEAS: This scale, developed by Gulec and Intepeler in 2012, has 3 factors. The 1st factor was named "Medical Error Perception" (MEP), the 2nd factor was named "Medical Error Attitude (MEA) and 3rd factor was named "Reasons for Medical Error" (RME). The final version of MEAS is made up of 16 items and it is in the type of five-item Likert. The total scoring range of the scale is between $16-80$. Two items on the scale are scored inversely. The cut-point of the scale was determined as 3. ME attitudes of the staff members getting an average below 3 in the scale are evaluated to be negative, ME attitudes of those getting 3 and over are evaluated to be positive. While the negative attitude indicates that the staff members have a low awareness of the significance of ME and error reporting, the positive attitude shows that there is a high level of awareness among staff members for the significance of medical errors and error reporting. The scoring and assessment criteria specified for the whole scale are regarded in the same way also for all sub-items of the scale. The Cronbach's Alpha reliability coefficient implemented for the purpose of testing internal consistency, one of the reliability indicators of MEAS and its subitems, was reported to be 0.75 for the whole scale. As for the reliability coefficients of the internal consistency of the sub-items of the scale, they were disclosed as 0.74 for MEP item, as 0.62 for MEA item, as 0.60 for RME item.

\section{Results}

The mean age of the participants in the study was $22.02 \pm 3.33$, and $\% 78.3$ of them were females (the rate of female students in the department was \%77.6). The rate of those with a chronic illness was $\% 3.4$, the rate of those that spend the majority of their lives in an urban area was \%78.3. In this study, the pretest score from METSN is $217.51 \pm 15.14$ (177 - 245), the posttest score from METSN is 220.18 \pm 15.39 (178 - 244), the pretest score from MEAS is $62.71 \pm 5.24(52-75)$, and the posttest score from MEAS is $64.21 \pm 5.18$ (52 - 73) when mean \pm sd scores are taken into account. The Cronbach's Alpha value in the pretest from METSN 0.899; it is 0.925 in the posttest from METSN. The Cronbach's Alpha value in the pretest from MEAS 0.563 ; it is 0.634 in the posttest from MEAS.

No characteristics of the participants shown in Table 1 such as age group, gender, the place of the residence occupied over a long period, etc. made a difference regarding the group the participants were placed in $(\mathrm{p}>0.05)$.

As can be seen in Table 2, a difference was found in the posttest score distributions for MTI, F, $\mathrm{HI}$, and $\mathrm{C}$ sub-items of METSN in terms of the groups of the participants $(\mathrm{p}<0.05)$. In this study, the posttest value of the sub-item for $\mathrm{C}$, the pretest value of the sub-item of MEP, the posttest median values of the sub-item for MEA from METSN of the FFEG are higher in such a way to create a difference ( $p$ $<0.05)$. As for the values for the ITG, the posttest values for sub-items of falls, medication and transfusion implementations for METSN, the posttest value of the total score from MEAS and the posttest value of the sub-item for MEA are higher in a way to make a difference $(p<0.05)$. In the control group, no difference was found regarding both the total score of the scales used and their scores of subitems $(p>0.05)$. Although it did not create a significant difference in the study $(p>0.05)$, it was observed that there was a higher increase in the posttest scores of the participants in ITG in comparison to their pretest scores from both METSN and MEAS. 
Table 1. Distribution of some characteristics of the participants in accordance with the group they are placed in $(\mathrm{N}=60)$

\begin{tabular}{|c|c|c|c|c|c|c|c|}
\hline & \multicolumn{2}{|c|}{ FFEG $^{\mathrm{a}}(\mathbf{n}=20)$} & \multicolumn{2}{|c|}{ ITG $^{\mathbf{b}}(\mathbf{n}=20)$} & \multicolumn{2}{|c|}{$\mathrm{CG}^{\mathrm{c}}(\mathbf{n}=20)$} & \\
\hline & $\mathbf{n}$ & $\% *$ & $\mathbf{n}$ & $\% *$ & $\mathbf{n}$ & $\% *$ & \\
\hline \multicolumn{8}{|l|}{ Age group } \\
\hline Between 19-21 age & 13 & 33.3 & 15 & 38.5 & 11 & 28.2 & $\chi^{2}=1.758$ \\
\hline 22 and above & 7 & 33.3 & 5 & 23.8 & 9 & 42.9 & $\mathrm{p}=0.41$ \\
\hline \multicolumn{8}{|l|}{ Gender } \\
\hline Male & 16 & 34.0 & 16 & 34.0 & 15 & 31.9 & $\chi^{2}=0.196$ \\
\hline Woman & 4 & 30.8 & 4 & 30.8 & 5 & 38.5 & $\mathrm{p}=0.90$ \\
\hline \multicolumn{8}{|l|}{ Longest living area } \\
\hline Rural area & 5 & 38.5 & 3 & 23.1 & 5 & 38.5 & $\chi^{2}=0.786$ \\
\hline Urban area & 15 & 31.9 & 17 & 36.2 & 15 & 31.9 & $\mathrm{p}=0.67$ \\
\hline \multicolumn{8}{|l|}{ Income perception } \\
\hline Enough & 13 & 37.1 & 9 & 25.7 & 13 & 37.1 & $\chi^{2}=2.194$ \\
\hline Insufficient & 7 & 28.0 & 11 & 44.0 & 7 & 28.0 & $\mathrm{p}=0.334$ \\
\hline \multicolumn{8}{|c|}{ Do you have a habit of smoking, drinking alcohol, or hookah? } \\
\hline Yes & 5 & 38.5 & 5 & 38.5 & 3 & 23.1 & $\chi^{2}=0.786$ \\
\hline No & 15 & 31.9 & 15 & 31.9 & 17 & 36.2 & $p=0.67$ \\
\hline \multicolumn{8}{|c|}{ Does he have a chronic disease? } \\
\hline Yes & 0 & 0.0 & 2 & 100.0 & 0 & 0.0 & $\chi^{2}=4.358$ \\
\hline No & 20 & 35.1 & 17 & 29.8 & 20 & 35.1 & $\mathrm{p}=0.11$ \\
\hline \multicolumn{8}{|c|}{ Is the profession your own choice? } \\
\hline Yes & 18 & 32.7 & 19 & 34.5 & 18 & 32.7 & $\chi^{2}=0.436$ \\
\hline No & 2 & 40.0 & 1 & 20.0 & 2 & 40.0 & $\mathrm{p}=0.80$ \\
\hline \multicolumn{8}{|c|}{ Is he happy with his job? } \\
\hline Yes & 17 & 38.6 & 14 & 31.8 & 13 & 29.5 & \\
\hline No & 0 & 0.0 & 1 & 33.3 & 2 & 66.7 & $\chi^{2}=3.206$ \\
\hline No idea & 3 & 23.0 & 5 & 38.5 & 5 & 38.5 & $\mathrm{p}=0.52$ \\
\hline \multicolumn{8}{|c|}{ If he made a medical mistake, would he report it? } \\
\hline Yes & 19 & 32.8 & 19 & 32.8 & 20 & 34.5 & $\chi^{2}=1.034$ \\
\hline No & 1 & 50.0 & 1 & 50.0 & 0 & 0.0 & $\mathrm{p}=0.59$ \\
\hline \multicolumn{8}{|c|}{ Would he report your friend's ME/M? } \\
\hline Yes & 18 & 31.6 & 19 & 33.3 & 20 & 35.1 & $\chi^{2}=2.105$ \\
\hline No & 2 & 66.7 & 1 & 33.3 & 0 & 0.0 & $p=0.34$ \\
\hline
\end{tabular}

${ }^{a}$ Face-to-Face Education Group; ${ }^{b}$ Information Technology Group; ${ }^{c}$ Control group

* The line percentage was regarded.

The state of difference between the total pretest and posttest scores of the participants from METSN and MEAS and some characteristics of participants is shown in Table 3. According to this, the pretest score of those deeming their income to be sufficient from MEAS is higher $(p<0.05)$. In the study, the posttest score from MEAS was found to be higher in those with a chronic disease and in those saying that they wouldn't report it if they committed a medical error $(\mathrm{p}<0.05)$. 
Int. J. of Health Serv. Res. and Policy (2020) 5(2):111-122

Table 2. Distribution of the pretest and posttest scores for METSN and MEAS in total and sub-items in terms of participants' groups $(\mathrm{N}=60)$

\begin{tabular}{|c|c|c|c|c|c|}
\hline \multicolumn{2}{|c|}{ Characteristics } & $\begin{array}{c}\text { FFEG }^{\mathbf{a}}(\mathbf{n}=\mathbf{2 0}) \\
\text { Mean } \pm \text { SD or Mean } \\
\text { Rank } \\
(\text { Min-Max })\end{array}$ & $\begin{array}{c}\text { ITG }^{\mathbf{b}}(\mathbf{n}=20) \\
\text { Mean } \pm \text { SD or Mean } \\
\text { Rank } \\
(\text { Min-Max })\end{array}$ & $\begin{array}{c}\mathbf{C G}^{\mathbf{c}}(\mathbf{n}=20) \\
\text { Mean } \pm \text { SD or Mean } \\
\text { Rank } \\
(\text { Min-Max })\end{array}$ & $\begin{array}{c}\text { Test } \\
\text { value }^{* * *}\end{array}$ \\
\hline \multirow{2}{*}{ METSN $^{d}$} & Pre-test & $222.00(195.00-245.00)$ & $220.00(177.00-242.00)$ & $222.00(181.00-237.00)$ & $\begin{array}{c}\mathrm{KW}=3.510 \\
\mathrm{p}=0.173\end{array}$ \\
\hline & Post-test & $227.50(196.00-244.00)$ & $222.00(178.00-242.00)$ & $222.50(190.00-237.00)$ & $\begin{array}{c}\mathrm{KW}=3.186, \\
\mathrm{p}=0.203\end{array}$ \\
\hline \multicolumn{2}{|c|}{ Test* } & $Z=-0.906, p=0.365$ & $\mathrm{Z}=-1.309, \mathrm{p}=0.191$ & $\mathrm{Z}=-0.561, \mathrm{p}=0.575$ & \\
\hline \multirow{2}{*}{ MTI $^{\mathrm{d} 1}$} & Pre-test & $85.00(74.00-90.00)$ & $81.00(63.00-90.00)$ & $84.00(57.00-88.00)$ & $\begin{array}{c}\mathrm{KW}=1.858 \\
\mathrm{p}=0.395\end{array}$ \\
\hline & Post-test & $84.50(76.00-89.00)$ & $83.00(68.00-90.00)$ & $83.00(69.00-90.00)$ & $\begin{array}{c}\mathrm{KW}=7.705, \\
\mathbf{p}=\mathbf{0 . 2 0 1}\end{array}$ \\
\hline \multicolumn{2}{|c|}{ Test* } & $\mathrm{Z}=-0.303, p=0.762$ & $Z=-2.601, \mathbf{p}=\mathbf{0 . 0 0 9}$ & $Z=-0.526, p=0.599$ & \\
\hline \multirow{2}{*}{$F^{\mathrm{d} 2}$} & Pre-test & $23.00(15.00-25.00)$ & $21.00(18.00-25.00)$ & $23.00(13.00-25.00)$ & $\begin{array}{c}\mathrm{KW}=0.762, \\
\mathrm{p}=0.683\end{array}$ \\
\hline & Post-test & $23.00(19.00-25.00)$ & $23.00(19.00-25.00)$ & $23.00(17.00-25.00)$ & $\begin{array}{c}\mathrm{KW}=6.712, \\
\mathbf{p}=\mathbf{0 . 0 3 5}\end{array}$ \\
\hline \multicolumn{2}{|c|}{ Test* } & $Z=-0.635, p=0.526$ & $Z=-2.071, \mathbf{p}=\mathbf{0 . 0 3 8}$ & $\mathrm{Z}=-0.088, \mathrm{p}=0.930$ & \\
\hline \multirow{2}{*}{$\mathbf{H I}^{\mathrm{d} 3}$} & Pre-test & $56.50(48.00-60.00)$ & $54.00(47.00-59.00)$ & $55.00(45.00-60.00)$ & $\begin{array}{c}\mathrm{KW}=0.563 \\
\mathrm{p}=0.755\end{array}$ \\
\hline & Post-test & $57.00(48.00-60.00)$ & $55.50(46.00-60.00)$ & $56.00(43.00-60.00)$ & $\begin{array}{c}\mathrm{KW}=5.981, \\
\mathbf{p}=\mathbf{0 . 0 5 0}\end{array}$ \\
\hline \multicolumn{2}{|c|}{ Test* } & $Z=-0.674, p=0.500$ & $\mathrm{Z}=-1.380, \mathrm{p}=0.168$ & $\mathrm{Z}=-0.172, \mathrm{p}=0.864$ & \\
\hline \multirow{2}{*}{$\mathbf{P M} / \mathbf{M S}^{\mathrm{d} \mathbf{4}}$} & Pre-test & $38.50(30.00-45.00)$ & $36.00(27.00-45.00)$ & $39.00(27.00-45.00)$ & $\begin{array}{c}\mathrm{KW}=3.287 \\
\mathrm{p}=0.193\end{array}$ \\
\hline & Post-test & $39.50(32.00-45.00)$ & $38.00(23.00-44.00)$ & $38.00(29.00-44.00)$ & $\begin{array}{c}\mathrm{KW}=3.874, \\
\mathrm{p}=0.144\end{array}$ \\
\hline \multicolumn{2}{|c|}{ Test* } & $\mathrm{Z}=-1.178, \mathrm{p}=0.239$ & $Z=-0.618, p=0.537$ & $Z=-0.285, p=0.775$ & \\
\hline \multirow{2}{*}{$C^{d 5}$} & Pre-test & $21.50(5.00-25.00)$ & $24.00(16.00-25.00)$ & $22.00(5.00-25.00)$ & $\begin{array}{c}\mathrm{KW}=1.137 \\
\mathrm{p}=0.566\end{array}$ \\
\hline & Post-test & $24.00(19.00-25.00)$ & $24.00(8.00-25.00)$ & $23.00(12.00-25.00)$ & $\begin{array}{c}\mathrm{KW}=10.35 \\
\mathbf{p}=\mathbf{0 . 0 0 6}\end{array}$ \\
\hline \multicolumn{2}{|c|}{ Test* } & $Z=-2.545, \mathbf{p}=\mathbf{0 . 0 1 1}$ & $\mathrm{Z}=-0.929, \mathrm{p}=0.353$ & $\mathrm{Z}=-1.575, \mathrm{p}=0.115$ & \\
\hline \multirow{2}{*}{ MEAS $^{\mathbf{e}}$} & Pre-test & $61.80 \pm 5.86$ & $61.90 \pm 5.37$ & $62.49 \pm 4.18$ & $\begin{array}{l}F=1.674 \\
p=0.197\end{array}$ \\
\hline & Post-test & $64.70 \pm 3.97$ & $64.45 \pm 5.14$ & $63.50 \pm 6.36$ & $\begin{array}{l}\mathrm{F}=0.291 \\
\mathrm{p}=0.749\end{array}$ \\
\hline \multicolumn{2}{|c|}{ Test* } & $\mathrm{t}=-1.962, \mathrm{p}=0.065$ & $\mathrm{t}=-3.422, \mathbf{p}=\mathbf{0 . 0 0 3}$ & $\mathrm{t}=0.836, \mathrm{p}=0.414$ & \\
\hline \multirow{2}{*}{ MEP $^{\mathbf{e}}$} & Pre-test & $6.20 \pm 1.36$ & $6.15 \pm 1.59$ & $5.80 \pm 1.36$ & $\begin{array}{l}F=0.455 \\
p=0.637\end{array}$ \\
\hline & Post-test & $5.35 \pm 1.26$ & $5.95 \pm 1.76$ & $5.80 \pm 1.39$ & $\begin{array}{l}F=0.877 \\
p=0.421\end{array}$ \\
\hline \multicolumn{2}{|c|}{ Test* } & $\mathrm{t}=2.429, \mathbf{p}=\mathbf{0 . 0 2 5}$ & $\mathrm{t}=0.940, \mathrm{p}=0.359$ & $\mathrm{t}=0.000, \mathrm{p}=1.000$ & \\
\hline \multirow{2}{*}{ MEA $^{\mathrm{e} 2}$} & Pre-test & $28.05 \pm 3.51$ & $28.85 \pm 3.21$ & $29.65 \pm 2.77$ & $\begin{array}{l}F=1.262 \\
p=0.291\end{array}$ \\
\hline & Post-test & $29.90 \pm 2.12$ & $30.05 \pm 2.35$ & $28.85 \pm 2.99$ & $\begin{array}{l}F=1.349 \\
p=0.268\end{array}$ \\
\hline \multicolumn{2}{|c|}{ Test** } & $\mathrm{t}=-2.325, \mathbf{p}=\mathbf{0 . 0 3 1}$ & $\mathrm{t}=-2.108, \mathbf{p}=\mathbf{0 . 0 4 9}$ & $\mathrm{t}=1.228, \mathrm{p}=0.234$ & \\
\hline \multirow{2}{*}{$\mathbf{R M E}^{\mathrm{e} 3}$} & Pre-test & $27.55 \pm 3.06$ & $26.90 \pm 3.00$ & $29.00 \pm 3.17$ & $\begin{array}{l}\mathrm{F}=2.428 \\
\mathrm{p}=0.097\end{array}$ \\
\hline & Post-test & $29.45 \pm 2.87$ & $28.45 \pm 3.08$ & $28.85 \pm 4.23$ & $\begin{array}{l}F=0.426 \\
p=0.655\end{array}$ \\
\hline \multicolumn{2}{|l|}{ Test* } & $\mathrm{t}=-2.027, \mathrm{p}=0.057$ & $\mathrm{t}=-2.153, \mathbf{p}=\mathbf{0 . 0 4 4}$ & $\mathrm{t}=0.183, \mathrm{p}=0.857$ & \\
\hline
\end{tabular}

${ }^{\mathrm{a}}$ Face-to-Face Education Group, ${ }^{\mathrm{b}}$ Information Technology Group, ${ }^{\mathrm{c}}$ Control group,

${ }^{\mathrm{d}}$ Medical Error Tendency Scale for Nurses; ${ }^{\mathrm{d} 1}$ Medication and Transfusion Implementations', ${ }^{\mathrm{d} 2} \mathrm{Falls}$, ${ }^{\mathrm{d} 3}$ Hospital Infections,

${ }^{\mathrm{d} 4}$ Patient Monitoring/Material Safety, ${ }^{\mathrm{d} 5}$ Communication;

${ }^{\mathrm{e}}$ Medical Error Attitude Scale, ${ }^{\mathrm{e} 1}$ Medical Error Perception, ${ }^{\mathrm{e} 2}$ Medical Error Attitude, ${ }^{\mathrm{e} 3}$ Reasons for Medical Error,

*Paired-Samples T-test / Wilcoxon Signed Ranks test, **One-Way ANOVA / KW: Kruskall Wallis test 
Table 3. Distribution of the pretest and posttest scores of the participants from METSN and MEAS in terms of some of the participants' characteristics $(\mathrm{N}=60)$

\begin{tabular}{|c|c|c|c|c|}
\hline Characteristics & $\begin{array}{c}\text { METSN }^{\text {a }} \text { Pretest } \\
\text { Mean } \pm \text { SD / } \\
\text { Mean Rank }\end{array}$ & $\begin{array}{c}\text { METSN }^{\text {a }} \text { Posttest } \\
\text { Mean } \pm \text { SD / } \\
\text { Mean Rank }\end{array}$ & $\begin{array}{c}\text { MEAS }^{\text {b Pretest }} \\
\text { Mean } \pm \text { SD / } \\
\text { Mean Rank }\end{array}$ & $\begin{array}{c}\text { MEAS }^{\mathrm{b}} \text { Posttest } \\
\text { Mean } \pm \text { SD / } \\
\text { Mean Rank }\end{array}$ \\
\hline \multicolumn{5}{|c|}{ Income perception } \\
\hline Enough & 31.26 & 32.63 & $63.91 \pm 5.61$ & $65.31 \pm 4.89$ \\
\hline Insufficient & 29.44 & 27.52 & $61.04 \pm 4.24$ & $62.68 \pm 5.28$ \\
\hline Test* & $\begin{array}{c}\mathrm{U}=411.00 \\
\mathrm{p}=0.691\end{array}$ & $\begin{array}{c}\mathrm{U}=363.00 \\
\mathrm{p}=0.264\end{array}$ & $\begin{array}{l}t=2.256, \\
p=\mathbf{0 . 0 2 8}\end{array}$ & $\begin{array}{c}\mathrm{t}=49.336 \\
\mathrm{p}=0.056\end{array}$ \\
\hline \multicolumn{5}{|c|}{ Does he have a chronic disease? } \\
\hline Yes & 27.75 & 34.25 & $65.50 \pm 4.94$ & $72.00 \pm 1.41$ \\
\hline No & 30.08 & 29.85 & $62.66 \pm 5.30$ & $63.89 \pm 5.09$ \\
\hline Test* & $\mathrm{U}=52.50, \mathrm{p}=0.852$ & $\mathrm{U}=48.50, \mathrm{p}=0.731$ & $\mathrm{t}=0.794, \mathrm{p}=0.565$ & $\mathrm{t}=6.720, \mathbf{p}=\mathbf{0 . 0 1 9}$ \\
\hline \multicolumn{5}{|c|}{ If he made a medical mistake, would he report it? } \\
\hline Yes & 30.53 & 30.31 & $62.55 \pm 5.22$ & $64.12 \pm 5.25$ \\
\hline No & 29.75 & 36.00 & $67.50 \pm 4.94$ & $67.00 \pm 0.00$ \\
\hline Test* & $\mathrm{U}=56.50, \mathrm{p}=0.950$ & $\mathrm{U}=47.00, \mathrm{p}=0.678$ & $\mathrm{t}=-1.319, \mathrm{p}=0.385$ & $\mathrm{t}=-4.175, \mathbf{p}=\mathbf{0 . 0 0 1}$ \\
\hline
\end{tabular}

${ }^{a}$ Medical Error Tendency Scale for Nurses, ${ }^{b}$ Medical Error Attitude Scale, ${ }^{*} t$ : Independent Samples Ttest/U: Mann-Whitney U Test, F: One-Way ANOVA

The relationship between the total pretest and posttest scores of the participants from METSN and MEAS is shown in Table 4. a positive, moderate relationship was found between the pretest and posttest scores from both scales $(\mathrm{p}<0.05)$.

Table 4. The Relationship between the total pretest and posttest scores of participants from METSN and MEAS $(\mathrm{N}=60) *$

\begin{tabular}{|c|c|c|c|c|c|}
\hline & & $\begin{array}{c}\text { METSN }^{\mathrm{a}} \\
\text { Pretest }\end{array}$ & $\begin{array}{c}\text { METSN }^{a} \\
\text { Posttest }\end{array}$ & $\begin{array}{l}\text { MEAS }^{\mathbf{b}} \\
\text { Pretest }\end{array}$ & $\begin{array}{l}\text { MEAS }^{\mathbf{b}} \\
\text { Posttest }\end{array}$ \\
\hline METSN Pretest & Rho & 1 & & & \\
\hline & $\mathbf{p}$ & - & & & \\
\hline METSN Posttest & Rho & $0.437 * *$ & 1 & & \\
\hline & $\mathbf{p}$ & 0.001 & - & & \\
\hline MEAS Pretest & Rho & -0.133 & -0.172 & 1 & \\
\hline & $\mathbf{p}$ & 0.310 & 0.190 & - & \\
\hline MEAS Posttest & Rho & -0.069 & 0.023 & $0.472^{* *}$ & 1 \\
\hline & $\mathbf{p}$ & 0.601 & 0.859 & 0.001 & - \\
\hline
\end{tabular}

${ }^{a}$ Medical Error Tendency Scale for Nurses, ${ }^{b}$ Medical Error Attitude Scale

* Spearman correlation analysis was implemented. 


\section{Discussion}

There were two objectives in this study with a pretest-posttest comparison and with the randomized-controlled trial method, the first of which was to determine whether any difference emerged between participants' scores from METSN and MEAS in terms of the methods employed in the intervention. The second objective of the study was to determine whether the desired characteristics created any difference in the scores from METSN and MEAS. The result that primarily attracts attention in the study is the attitudes of the participants regarding the reasons for ME / M. The participants specified among the top three reasons inexperience in the hospital, stress, and lack of knowledge, and they indicated among the lowest three reasons the long periods of working and presence of excessive protocols-procedures regarding implementations/incomprehensibility of protocols-procedures, not paying attention to shift changes and dissatisfaction with the administrator. In the study carried out by In the literature, while excessive workload, exhaustion and lack of communication were found to be the reasons that most cause $\mathrm{ME} \mathrm{/} \mathrm{M}$; absence of on-the-job training, dislike-negligence of the profession and administrative problems were reported to be the last three reasons that cause ME / M [18-21].

The second conclusion of the study is that the methods employed in intervention do not make a difference in the total scores from METSN and MEAS. However, it was observed that a difference emerged in scores in the items of communication, ME perception, and ME attitude in the face-to-face education group. It was found that a difference emerged in the sub-items of medication and transfusion implementations, falls, the total score from MEAS, and MEA sub-dimensions in the group where Whatsapp and Messenger were used as the information technology. On the other hand, the situation regarded as significant is the excess of the proportional increase in the posttest scores of the participants in ITG from METSN and MEAS. In a study by Sezer et al where whether online and traditional methods create any difference in on-the-job training is assessed, it was reported that the posttest scores of the intervention group rose in a similar way to those in this study [22]. In one study, 500 obstetricians and 500 pediatricians were asked whether they gave any recommendation to their patients regarding the consumption of chicken products. This study not only reveals the impact of traditional communication tools once again but also the fact that doctors have been opting for the Internet and social media tools in getting information and that they regard these tools as important references with respect to treatment options [23].

The third result of the study is that among the desired characteristics, perception of income level, the state of chronic illness, and variables regarding reporting of ME/M in case of the commitment of these create a difference in terms of METSN and MEAS. Socio-demographic characteristics assessed in the study conducted by Guven et al [24]. Through cooperation with volunteering nurses working in a state hospital did not create any difference in terms of ME / M attitude. In the study by Ozen et al., the score averages in those at the age of 31 and over and in women from METSN were found to be high enough to create a difference [18]. In another study was reported that total score averages and the score averages from some sub-items from METSN were higher in women, in those that deemed their income to be insufficient and in those dissatisfied with their jobs [25]. The reason for the differences has been considered to be the fact that the sampling group was working.

The last finding of the study is the result of intervention methods for pretest and posttest scores. It was observed that the score values of the participants regarding ME / M tendencies and attitudes after the interventions implemented increased positively and moderately. This situation has been interpreted 
in such a way that it is thought that updates and reinforcements of information for individuals to increase ME/M tendency and attitude are beneficial. The use of web-based networks has been explained as pedagogical tools in the literature and it has been stated that the educational use of such tools will be beneficial [26-28]. The finding that comes before us in observations in our day regarding this age group is that the source of information for those that continue their daily lives in the allure of social media is now the digital world. Therefore, the result is attention-grabbing. It is deemed that the awareness-raising regarding health education or implementations rendered in general through information technologies will be convenient.

\section{Conclusions}

In this study where whether face-to-face education methods and methods of education through information technologies make a difference in ME/M tendency and attitude was assessed, and it was found that there was no difference between both intervention methods in terms of efficiency. ME / M tendency decreased and levels of positive attitude increased after both intervention methods. None of the socio-demographic characteristics made a difference in the total scores for tendency and attitude; however, some of them made a difference in sub-item scores. It will be beneficial to re-conduct this study both on other samples and in various disciplines providing health services.

Ethical Statement: All procedures performed in studies involving human participants were in accordance with the ethical standards of the institutional and/or national research committee and with the 1964 Helsinki declaration and its later amendments or comparable ethical standards.

This study is approved by Bingöl University Ethics Committee ( 92342550/044;19.06.2019).

Funding sources: The work did not receive any other grant from funding agencies in the public, commercial, or not-for-profit sectors.

Declaration of Conflict Interest: The authors declare no further conflicts of interest. For any conflicts of interest outside the submitted work, all authors filled in the ICMJE form that is available upon request. Acknowledgments: We thank all of the participants.

\section{References}

[1] Merriam Webster, Malpractise definition. https://www.merriamwebster.com/dictionary/malpractice.

[2] JCAHO, 2006. Sentinel Event Statistics, Retrieved from www.jointcommission.org/Library/TM physicians/mp_11_06.htm

[3] Avsar, G., Atabek Armutcu, E., Karaman Ozlu, Z., "Determining the level of tendency in malpractice of nurses: A hospital sample”, HSP, 3(2), 115-122, 2016. doi 10.17681/hsp.86420

[4] Akgun Sahin, Z., Kardas Ozdemir, F., "Examination of the tendency for nursing malpractice and affecting factors", HEAD. 12(3), 210-214, 2015. doi 10.5222/HEAD.2015.210

[5] Ozata, M., Altunkan, H., "Frequency of medical errors in hospitals, determination of medical error types and medical errors: Konya sample", Journal of Medical Research, 8(2), 100-111, 2010. https://www.medikalakademi.com.tr/?get_group_doc=20/1460364096-hastane-tibbihata.pdf 
[6] Kırsan, M., Akın Korhan, E, Simsek, S., Ozciftci, S., Ceylan B. "Medication errors in Nursing practice: A sysytematic Review", Turkiye Klinikleri J Nurs Sci, 11(1),35-51, 2019. doi 10.5336/nurses.2018-62052

[7] Kahriman, I., Ozturk, H. "Evaluating medical errors made by nurses during their diagnosis, treatment and care practices", J Clin Nurs. 25(19-20), 2884-24, 2016. doi 10.1111/jocn.13341

[8] Joon, L.M., Yeon, L.M., Won, M.H. "Nurses' perception of nursing malpractice liability insurance", Indian Journal of Health Research \& Development, 10(11), 4481-4486, 2019. doi: 10.5958/0976-5506.2019.04313.4

[9] Menachemi, N., Shewchuk, R.M., O’Connor, S.J., Berner, E.S., Allison, J.J., "Perceptions of medical errors by internal medicine residents: Development and validation of a new scale", Quality Management in Health Care, 14(3), 144- 154, 2005.

https://www.ncbi.nlm.nih.gov/pubmed/16027592

[10] World Health Organization 2019. World Alliance for Patient Safety Forward Programme 2005. Retrieved from http://www. who.int/patientsafety/en/brochure_final. pdf

[11] Akalın, H.E., "Patient safety in intensive care units", Journal of Intensive Care, 5(3), 141-146, 2005. http://www.yogunbakimdergisi.org/managete/fu_folder/2005-03/2005-5-3-141-146.pdf

[12] Ozer, O., Tastan Set, T., Cayır, Y., Sener, M.T., "Malpractice", Dicle Medical Journal, 42(3), 394-397, 2015. doi 10.5798/diclemedj.0921.2015.03.0597

[13] Moo, 2019. Sharing and Communication Infographic. Retrieved from https://www.moo.com/us/partner/sharing-and-communication/

[14] Ugwu, L.O., Oyebisi, T.O., Ilori, M.O., Adagunodo, E.R., "Organizational impact of information technology on the banking and insurance sector in Nigeria", Technovation, 20(12), 711-721, 2000. doi 10.1016/S0166-4972(00)00013-4

[15] Plano Clark, V.L., Creswell, J.W., Understanding Research: A consumer's guide. Upper Saddle River, NJ: Pearson Education. 2015.

[16] Buyukozturk, S., K1lıc Cakmak, E., Akgun, O.E., Karadeniz, S., Demirel, F., Scientific Research Methods, Ankara: Pegem.2011

[17] Arıkan, R., Research Methods and Techniques, Ankara: Nobel. 2013.

[18] Ozen, N., Onay, T., Terzioglu, F., "Determination of nurses' tendency to make medical errors and affecting factors", Journal of Health Sciences and Professions, 283-292, 2019. doi $10.17681 / \mathrm{hsp} .451510$

[19] Cevik Durmaz, Y., Dogan, R., "Malpractice tendency of nursing students at a public university", Urkish Studies. 15(2), 853-864, 2020 864. https://dx.doi.org/10.29228/TurkishStudies.37030

[20] Birgili, F., Sahin, M. "Determination of nursing students' medical errors", International Journal of Nursing, 6(1), 25-32,2019.doi: 10.15640/ijn.v6n1a4 
[21] Ozturk H., Kahriman, İ., Bahcecik, A.N., Sökmen, S., Calbayram, N., Altundag S, Kucuk, S. "The malpractices of student nurses in clinical practice in Turkey and their causes", J Pak med Assoc. 67(8), 1198-1205, 2017.

[22] Sezer, B., Karaoglan Yılmaz, F.G., Yılmaz, R., "Comparison of online and traditional face-toface in-service training practices: An experimental study", Journal of Cukurova University Faculty of Education, 46(1), 264-288, 2017. doi 10.14812/cuefd.311737

[23] Bir, A.A., Doctors' Information Source Is Also Popular Media!. Health Communication Association. 2019. Retrieved from http://saglikiletisimi.org/doktorlarin-bilgi-kaynagi-dapopulermedya

[24] Guven, S.D., Sahan, S., Unsal, A., "Nurses' attitudes for medical errors", Izlek Academic Journal, 2(2), 75-85, 2019. https://dergipark.org.tr/tr/download/article-file/799882

[25] Yigitbas, C., Oguzhan, H., Tercan, B., Bulut, A., Bulut, A., "Nurses' Perception, Attitudes and Behaviors Concerning Malpractice", Anadolu Klinigi 21(3), 207-214, 2016. https://dergipark.org.tr/tr/download/article-file/310310

[26] Albion, P.R., "Web 2.0 in teacher education: Two Imperatives for Action, Computers in the Schools", Journal Computers in the Schools, 25(3-4), 181-198, 2008. doi.org/10.1080/07380560802368173

[27] Ferdig, R.E., "Editorial: Examining social software in teacher education”, Journal of Technology and Teacher Education, 15(1), 5-10, 2007. http://www.editlib.org/p/23518

[28] McLoughlin, C., Lee, J.W., Social Software and Participatory Learning: Pedagogical Choices with Technology Affordances in the Web 2.0 Era. 2008. Singapore. Retrieved from https://pdfs.semanticscholar.org/52ac/3f2b3d75e6de176dce701afc0b469d7f949a.pdf 